Jurnal Ilmiah Ibnu Sina, 6(2), Oktober 2021, 215-222

p-ISSN: 2502-647X; e-ISSN: 2503-1902

\title{
ANALISIS KADAR VITAMIN C PADA KUBIS MERAH \\ (Brassica oleracea L. var capitata) YANG DIBUAT JUS DENGAN VARIASI LAMA PENYIMPANAN
}

\author{
Siska Nur A'ini*, Crescentiana Emy Dhurhania \\ Sekolah Tinggi Ilmu Kesehatan Nasional \\ *Email: siskanuraini960@gmail.com
}

Artikel diterima: 14 Mei 2021; Disetujui: 20 September 2021

DOI: https://doi.org/10.36387/jiis.v6i2.699

\begin{abstract}
ABSTRAK
Vitamin $\mathrm{C}$ merupakan zat berkhasiat antioksidan yang terkandung dalam kubis merah (Brassica oleracea L. var capitata). Umumnya masyarakat menyimpan bahan jus dalam lemari pendingin. Penelitian ini dilakukan untuk mengetahui pengaruh lama penyimpanan terhadap kadar vitamin $\mathrm{C}$ dalam kubis merah yang dibuat jus. Variasi lama penyimpanan yang digunakan adalah 1, 4, dan 7 hari dengan suhu penyimpanan $5{ }^{\circ} \mathrm{C}$. Uji kualitatif dengan pereaksi iodium, Fehling, dan ammonium molibdat memberikan hasil positif mengandung vitamin C. Uji kuantitatif dilakukan secara spektrofotometri UV-Vis pada panjang gelombang maksimal $570,5 \mathrm{~nm}$ dengan operating time pada menit ke-20 setelah larutan uji ditambah $\mathrm{H}_{2} \mathrm{SO}_{4}$ dan ammonium molibdat. Hasil uji kuantitatif menunjukkan kadar vitamin $\mathrm{C}$ pada hari pertama $63,92 \mathrm{mg} / 100 \mathrm{~g}$, pada hari keempat $63,32 \mathrm{mg} / 100 \mathrm{~g}$, pada hari ketujuh $62,52 \mathrm{mg} / 100 \mathrm{~g}$ kubis merah dengan koefisien variasi $0,26 \%$. Uji Tukey menghasilkan nilai $\mathrm{p}$ lebih dari 0,05 yaitu 0,831 sehingga kadar vitamin $\mathrm{C}$ kubis merah yang dibuat jus pada hari ke-1, ke-4 dan ke-7 tidak berbeda signifikan.
\end{abstract}

Kata kunci: kubis merah, jus, vitamin C, lama penyimpanan.

\begin{abstract}
Vitamin $C$ is an antioxidant that is contained in red cabbage (Brassica oleracea L. var capitata). Generally, people store juice ingredients in the refrigerator. This research was carried out to determine the effect of storage time on vitamin $C$ levels in juiced red cabbage. The variation of storage time used was 1, 4, and 7 days with a storage temperature of $5^{\circ} \mathrm{C}$. Qualitative test using iodine, Fehling, and ammonium molybdate reagent gave positive results containing vitamin $C$. The quantitative test was carried out by $U V$-Vis spectrophotometry at a maximum wavelength of $570.5 \mathrm{~nm}$ with operating time at 20 minutes after the test solution was added with $\mathrm{H}_{2} \mathrm{SO}_{4}$ and ammonium molybdate. The quantitative test results showed that the level of vitamin C on the first day was $63.92 \mathrm{mg} / 100 \mathrm{~g}$, on the fourth day was $63.32 \mathrm{mg} / 100 \mathrm{~g}$, on the seventh day was $62.52 \mathrm{mg} / 100 \mathrm{~g}$ red cabbage with coefficients of variation $0.26 \%$. The Tukey test resulted in a $p$ value of more than 0.05 , ie 0.831, so that the levels of vitamin $C$ red cabbage juice made on the $1^{\text {st }}, 4^{\text {th }}$, and $7^{\text {th }}$ days were not significantly different.
\end{abstract}


Jurnal Ilmiah Ibnu Sina, 6(2), Oktober 2021, 215-222

p-ISSN: 2502-647X; e-ISSN: 2503-1902

Keywords: red cabbage, juice, vitamin C, storage time.

\section{PENDAHULUAN}

Kubis merah (Brassica

oleracea L. var capitata) merupakan tanaman pangan budidaya yang masih terbatas pemanfaatannya. Namun potensinya sebagai antioksidan telah banyak diteliti. Zat berkhasiat antioksidan yang terkandung dalam kubis merah antara lain senyawa fenolik, flavonoid, vitamin A, B, C (Pratama dkk, 2018; Putri dkk, 2017; Wahyuni, 2018).

Hasil penelitian Wahyuni (2018) telah membuktikan bahwa ekstrak etanol kubis merah memiliki aktivitas antioksidan yang sangat kuat dengan $\mathrm{IC}_{50} 44,64$ ppm. Namun pembuatan ekstrak relatif sulit jika diaplikasikan oleh masyarakat, sehingga penggunaan dalam bentuk jus lebih disarankan. Jus juga mampu menarik vitamin $\mathrm{C}$ lebih banyak karena mudah larut dalam air.

Tabel komposisi pangan

Indonesia (Kemenkes, 2018) menyatakan kubis merah mengandung vitamin $\mathrm{C}$ sebesar 50 mg/ 100 g. Penyimpanan pada suhu $5^{\circ} \mathrm{C}$ diharapkan dapat menjaga stabilitas kandungan vitamin $\mathrm{C}$ dengan menekan laju respirasi. Kubis bersifat mudah layu dan membusuk sehingga dapat mempengaruhi stabilitas kandungan zat aktif. Dengan demikian, perlu dilakukan penelitian untuk mengetahui pengaruh lama penyimpanan terhadap kadar vitamin C dalam kubis merah yang dibuat jus.

\section{METODE PENELITIAN}

\section{Alat Penelitian}

Alat-alat yang digunakan, yaitu: spektrofotometer UV-Vis (Shimadzu UV mini-1280), kuvet (Hellma Analytics 100.600-QG), neraca analitik (Ohaus pioneer PX224/E), sentrifuge (Oregon LC04S), blender, penyaring vakum dan alat-alat gelas yang lazim dalam kimia analisis.

\section{Bahan Penelitian}

Bahan-bahan yang digunakan dalam penelitian, terdiri dari: kubis merah (perkebunan dusun Sawit, Girirejo, Magelang), asam askorbat p.a. (Merck), asam oksalat p.a. (Merck), asam sulfat (Merck), 
Jurnal Ilmiah Ibnu Sina, 6(2), Oktober 2021, 215-222

p-ISSN: 2502-647X; e-ISSN: 2503-1902

iodium (Merck), Fehling A dan B (Merck), ammonium molibdat (Merck), air suling (Brataco).

\section{Preparasi Sampel}

Kubis merah dicuci bersih, lalu dipotong-potong dan dihomogenkan. Setelah itu potongan kubis merah ditimbang seksama $50 \quad \mathrm{~g}$ dan ditambah 100,0 $\mathrm{mL}$ asam oksalat $0,4 \%$, lalu dihaluskan dengan blender (Widiastuti, 2015). Jus kubis merah disaring dengan teknik penyaringan vakum dan filtrat diukur volumenya. Filtrat jus kubis merah dipipet 10,0 mL kemudian disentrifugasi selama 3 menit pada kecepatan $3000 \mathrm{rpm}$. Supernatan jernih hasil sentrifugasi digunakan untuk larutan uji vitamin C.

\section{Uji Kualitatif}

1. Uji dengan pereaksi iodium

Larutan uji ditambah iodum. Jika positif mengandung vitamin $\mathrm{C}$ maka warna iodium akan hilang (Tahir dkk, 2016).

2. Uji dengan pereaksi Fehling

Larutan uji ditambah Fehling A dan Fehling B sama banyak. Jika positif mengandung vitamin $\mathrm{C}$ maka akan terbentuk endapan merah bata setelah dipanaskan (Widiastuti, 2015).

3. Uji dengan ammonium molibdat Larutan uji ditambah ammonium molibdat. Jika positif mengandung vitamin $\mathrm{C}$ maka akan terbentuk warna biru (Tahir dkk, 2016).

\section{Uji Kuantitatif Vitamin C}

1. Pembuatan larutan baku vitamin $\mathrm{C}$

Zat baku asam askorbat ditimbang seksama lalu dilarutkan dengan asam oksalat $0,4 \%$ hingga diperoleh konsentrasi 1000 ppm (Tahir dkk, 2016).

2. Penentuan operating time

Larutan baku vitamin $\mathrm{C}$ dipipet 0,5 mL, ditambah 4,0 $\mathrm{mL} \mathrm{H}_{2} \mathrm{SO}_{4}$ $5 \%$, dan diencerkan dengan ammonium molibdat 5\% hingga 10,0 mL. Absorbansi diukur pada $570 \mathrm{~nm}$ hingga stabil.

3. Panjang gelombang maksimal Larutan baku vitamin $\mathrm{C}$ dipipet 0,5 mL, ditambah 4,0 $\mathrm{mL} \mathrm{H}_{2} \mathrm{SO}_{4}$ $5 \%$, dan diencerkan dengan ammonium molibdat 5\% hingga 10,0 mL (Tahir dkk, 2016). Larutan didiamkan hingga operating time, lalu absorbansi 
Jurnal Ilmiah Ibnu Sina, 6(2), Oktober 2021, 215-222

p-ISSN: 2502-647X; e-ISSN: 2503-1902

diukur pada panjang gelombang $550-600 \mathrm{~nm}$.

4. Pembuatan kurva baku

Larutan baku vitamin $\mathrm{C}$ dipipet 0,$2 ; 0,3 ; 0,4 ; 0,5 ;$ dan $0,6 \mathrm{~mL}$, lalu ditambah $4,0 \mathrm{~mL} \mathrm{H} \mathrm{H}_{2} \mathrm{SO}_{4} 5 \%$, dan diencerkan dengan ammonium molibdat 5\% hingga $10,0 \mathrm{~mL}$ (Tahir dkk, 2016). Larutan didiamkan hingga operating time, kemudian absorbansi diukur pada panjang gelombang maksimal. Kurva baku merupakan fungsi dari konsentrasi dan absorbansi.

5. Pengukuran kadar vitamin $\mathrm{C}$ Larutan uji dipipet 1,0 mL lalu ditambah 4,0 $\mathrm{mL} \mathrm{H}_{2} \mathrm{SO}_{4} 5 \%$, dan diencerkan dengan ammonium molibdat $5 \%$ hingga $10,0 \mathrm{~mL}$ (Tahir dkk, 2016). Larutan didiamkan hingga mencapai operating time, lalu absorbansi diukur pada panjang gelombang maksimal.

\section{Analisis Kadar Vitamin C}

Perhitungan kadar vitamin $\mathrm{C}$ menggunakan persamaan regresi linier dari kurva baku, yang dilanjutkan dengan analisis statistik dengan uji Tukey. Ketelitian metode analisis dinyatakan dengan koefisien variasi.

\section{HASIL DAN PEMBAHASAN}

Penelitian ini dilakukan untuk mengetahui pengaruh lama penyimpanan terhadap kadar vitamin C dalam kubis merah yang dibuat jus. Penyimpanan pada suhu $5^{\circ} \mathrm{C}$ bertujuan untuk menjaga kubis merah tetap segar sehingga kandungan vitamin $\mathrm{C}$ di dalamnya relatif stabil. Hasil orientasi lama penyimpanan kubis merah pada suhu $5^{\circ} \mathrm{C}$ menunjukkan bahwa tidak ada perubahan tekstur kubis pada minggu pertama. Pada minggu kedua kubis merah mulai layu dan membusuk dengan warna yang semakin gelap. Hal ini yang mendasari penentuan lama penyimpanan kubis merah yang tidak lebih dari satu minggu, sehingga masih layak dikonsumsi.

$$
\text { Pembuatan jus dilakukan }
$$
dengan perbandingan kubis merah dan pelarut 1:2 untuk mendapatkan tingkat kekentalan jus yang sesuai untuk dikonsumsi. Vitamin $\mathrm{C}$ dalam kubis merah akan ditarik oleh fase air karena vitamin $\mathrm{C}$ mudah larut dalam air. Penambahan asam oksalat saat 
Jurnal Ilmiah Ibnu Sina, 6(2), Oktober 2021, 215-222

p-ISSN: 2502-647X; e-ISSN: 2503-1902

preparasi sampel bertujuan untuk mencegah oksidasi vitamin $\mathrm{C}$.

Penyaringan jus kubis merah dilakukan dengan teknik pompa vakum untuk mendapatkan volume filtrat yang maksimal dalam waktu yang lebih cepat. Partikel halus dalam filtrat yang masih lolos dalam proses penyaringan dienapkan dengan sentrifugasi sehingga diperoleh supernatan jernih sebagai larutan uji.

Uji kualitatif dilakukan untuk memastikan bahwa jus kubis merah mengandung vitamin C. Pada uji kualitatif diperoleh hasil positif yang ditandai dengan kesesuaian perubahan warna terhadap pustaka setelah ditambah pereaksi, seperti yang disajikan pada tabel 1 .

Tabel 1. Hasil Uji Kualitatif Vitamin C pada Jus Kubis Merah

\begin{tabular}{|c|c|c|c|}
\hline Pereaksi & Hasil & Pustaka & Ket \\
\hline Iodium & $\begin{array}{l}\text { Warna } \\
\text { Iodium } \\
\text { hilang }\end{array}$ & $\begin{array}{c}\text { Warna } \\
\text { Iodium } \\
\text { hilang } \\
\text { (Tahir,2016) }\end{array}$ & + \\
\hline $\begin{array}{c}\text { Fehling A } \\
\text { dan B }\end{array}$ & $\begin{array}{c}\text { Endapan } \\
\text { merah } \\
\text { bata }\end{array}$ & $\begin{array}{c}\text { Endapan } \\
\text { merah bata } \\
\text { (Widiastuti, } \\
\text { 2015). }\end{array}$ & + \\
\hline $\begin{array}{l}\text { Ammonium } \\
\text { Molibdat }\end{array}$ & $\begin{array}{c}\text { Warna } \\
\text { biru } \\
\text { molibden }\end{array}$ & $\begin{array}{l}\text { Warna biru } \\
\text { molibden } \\
\text { (Tahir,2016) }\end{array}$ & + \\
\hline
\end{tabular}

Uji kuantitatif diawali dengan penentuan operating time yaitu waktu yang dibutuhkan vitamin $\mathrm{C}$ bereaksi sempurna dengan ammonium molibdat dalam suasana asam hingga terbentuk warna biru molibden. Absorbansi yang stabil diperoleh mulai menit ke-20 yang mengindikasikan bahwa telah terbentuk warna biru molibden yang stabil. Operating time pada penelitian ini serupa dengan penelitian Kamri dkk (2019). Hal tersebut didukung dengan hasil optimasi stabilitas pembentukan warna biru molibden yang tidak berbeda signifikan pada rentang 2030 menit (Sudjarwo, 2017).

Spektrum absorbansi vitamin C setelah ditambah asam sulfat sebagai pemberi suasana asam dan pereaksi ammonium molibdat, serta didiamkan 20 menit, dapat dilihat pada gambar 1. Nilai absorbansi tertinggi diperoleh pada panjang gelombang 570,5 nm. Dengan demikian pengukuran absorbansi pada tahap berikutnya dilakukan pada 570,5 nm setelah larutan didiamkan selama 20 menit. 


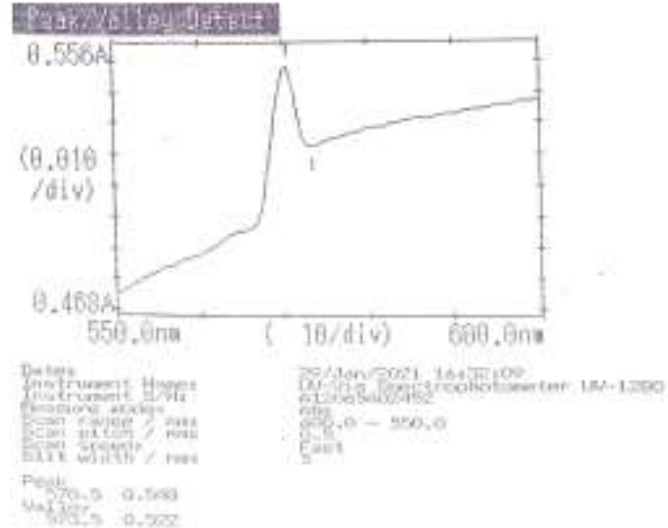

Gambar 1. Spektrum Absorbansi Vitamin C setelah Direaksikan dengan Asam Sulfat dan Ammonium Molibdat serta Didiamkan 20 menit

Kurva baku dibuat dari seri larutan baku pada rentang 20-60 ppm, dengan hasil yang telah disajikan pada gambar 2. Persamaan regresi linier yang dihasilkan yaitu $\mathrm{Y}$ $=00996 \mathrm{X}+0,1186$, dengan nilai koefisien korelasi 0,9998. Kurva baku yang diperoleh memiliki linieritas yang baik sehingga metode analisis yang digunakan mampu memberikan data absorbansi yang proporsional terhadap konsentrasi vitamin $\mathrm{C}$ dalam larutan uji. Oleh karena itu, absorbansi larutan pada rentang kadar 20-60 ppm digunakan sebagai daerah kerja saat pengukuran absorbansi pada tahap pengukuran kadar.

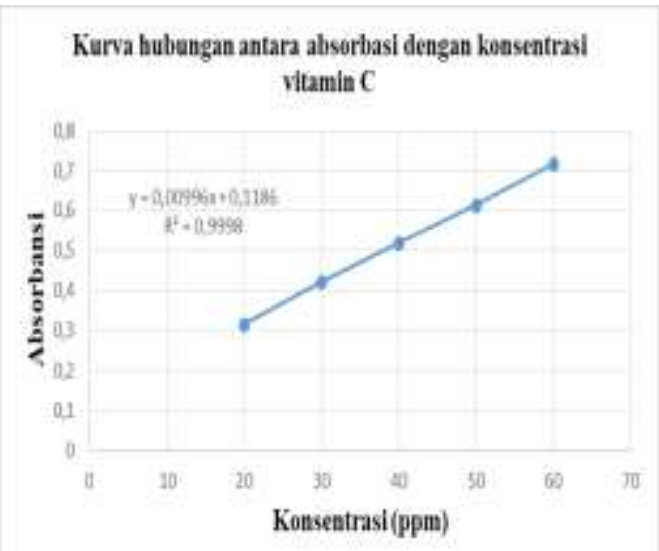

Gambar 2. Kurva Baku Vitamin C yang Diukur pada 570,5 nm setelah Direaksikan dengan Asam Sulfat dan Ammonium Molibdat serta Didiamkan 20 menit

Tahap selanjutnya dilakukan pengukuran kadar vitamin $\mathrm{C}$ dalam kubis merah yang telah disimpan pada suhu $5{ }^{\circ} \mathrm{C}$ dan dibuat jus pada berbagai hari penyimpanan, dengan hasil seperti yang telah dipaparkan pada tabel 2 .

Tabel 2. Kadar Vitamin C dalam Kubis Merah yang Disimpan pada Suhu ${ }^{\circ} \mathrm{C}$ dan Dibuat Jus pada Berbagai Hari Penyimpanan

\begin{tabular}{|c|c|c|c|c|}
\hline $\begin{array}{l}\text { Hari } \\
\text { ke- }\end{array}$ & $\begin{array}{c}\text { Re } \\
\text { pli } \\
\text { kasi }\end{array}$ & $\begin{array}{c}\text { Kadar } \\
\text { Vitamin C } \\
\text { (mg/100 g } \\
\text { kubis } \\
\text { merah) }\end{array}$ & $\begin{array}{c}\text { Rata- } \\
\text { rata } \\
\text { Kadar } \\
\text { (mg/100 } \\
\text { g kubis } \\
\text { merah) }\end{array}$ & $\begin{array}{l}\mathrm{KV} \\
(\%)\end{array}$ \\
\hline \multirow{3}{*}{1} & 1 & 63,72 & \multirow{3}{*}{63,92} & \multirow{3}{*}{$0,26 \%$} \\
\hline & 2 & 63,12 & & \\
\hline & 3 & 63,92 & & \\
\hline \multirow{3}{*}{4} & 1 & 63,12 & \multirow{3}{*}{63,32} & \multirow{3}{*}{$0,26 \%$} \\
\hline & 2 & 63,34 & & \\
\hline & 3 & 63,52 & & \\
\hline \multirow{3}{*}{7} & 1 & 62,32 & \multirow{3}{*}{62,52} & \multirow{3}{*}{$0,26 \%$} \\
\hline & 2 & 62,72 & & \\
\hline & 3 & 62,52 & & \\
\hline
\end{tabular}


Jurnal Ilmiah Ibnu Sina, 6(2), Oktober 2021, 215-222

p-ISSN: 2502-647X; e-ISSN: 2503-1902

Seluruh data pengukuran kadar memiliki nilai koefisien variasi $(\mathrm{KV})$ kurang dari $2 \%$, sehingga metode analisis yang digunakan memiliki ketelitian yang sangat baik. Rata-rata kadar vitamin $\mathrm{C}$ yang diperoleh menunjukkan bahwa lama penyimpanan kubis merah pada suhu $5{ }^{\circ} \mathrm{C}$ menurunkan kadar vitamin $\mathrm{C}$ dalam jus yang dibuat pada hari ke-1, ke-4, dan ke-7. Namun perlu dilakukan uji beda nyata dengan analisis statistic.

Analisis statistik diawali dengan Kolmogorov-Smirnov Test sebagai normality test untuk membuktikan bahwa data terdistribusi normal. Pada homogenity test menunjukkan bahwa homogenitas variasi populasi dari 3 petani yang berbeda telah dapat diterima. Nilai p pada uji analisis ragam lebih besar dari 0,05, yaitu 0,834, yang berarti kadar vitamin $\mathrm{C}$ tidak ada perbedaan signifikan. Demikian pula pada uji Tukey diperoleh nilai $\mathrm{p}$ lebih besar dari 0,05 , yaitu 0,831 , yang menunjukkan bahwa kadar vitamin $\mathrm{C}$ kubis merah yang dibuat jus pada hari ke-1, ke-4 dan ke-7 tidak berbeda signifikan.

\section{KESIMPULAN}

Kadar vitamin $\mathrm{C}$ dalam kubis merah yang dibuat jus pada hari pertama $63,92 \mathrm{mg} / 100 \mathrm{~g}$, pada hari keempat 63,32 mg/100 g, pada hari ketujuh $62,52 \mathrm{mg} / 100 \mathrm{~g}$ kubis merah dengan koefisien variasi $0,26 \%$. Lama penyimpanan kubis merah pada suhu $5{ }^{\circ} \mathrm{C}$ menurunkan kadar vitamin $\mathrm{C}$ dalam jus yang dibuat pada hari pertama, hari keempat, dan hari ketujuh, namun tidak berbeda signifikan.

\section{DAFTAR PUSTAKA}

Kamri, A.M., Abidin, Z., Sadjidin, S., Naid, T., 2019, Analisis Kadar Vitamin C pada Buah Delima (Punica granatum L.) Merah dan Putih secara Spektrofotometri UV-Vis, Window of Health: Jurnal Kesehatan, 2(2),155-161.

Kementerian Kesehatan Republik Indonesia, 2018, Tabel Komposisi Pangan Indonesia, Kementerian Kesehatan Republik Indonesia, Jakarta, 123.

Pratama, M., Aminah, Mas'ud, R.A., 2018, Efektivitas Pemanfaatan Potensi Senyawa Fenolik Kubis Ungu (Brassica Oleraceae var.capitata. L) secara Instrumen UV-Vis, Jurnal Fitofarmaka Indonesia, 5(2), 293-298. 
Jurnal Ilmiah Ibnu Sina, 6(2), Oktober 2021, 215-222

p-ISSN: 2502-647X; e-ISSN: 2503-1902

Putri, A.S., Bekti, E., Haryati, S., 2017, Kajian Pemanfaatan Kubis Merah (Brassica oleracea L.) sebagai Antioksidan dan Aplikasinya pada Kerupuk Kubis Merah, Laporan Penelitian Dosen, Universitas Semarang.

Sudjarwo, 2017, Optimization and Validation of VisibleSpectrophotometry Method for Determination Ascorbic Acid in Jeruk Bali (Citrus maxima) Fruit form Indonesia, International Journal of Pharmaceutical Quality Assurance, 8(2), 44-48.

Tahir, M., Hikmah, N., Rahmawati, 2016, Analisis Kandungan Vitamin $\mathrm{C}$ dan $\beta$-Karoten dalam Daun Kelor (Moringa oleifera Lam.) dengan Metode Spektrofotometri UV-Vis, Jurnal Fitofarmaka Indonesia, 3(1), 135-140.

Wahyuni, D.I., 2018, Uji Aktivitas Ekstrak Etanol dan Ekstrak Etil Asetat Kubis Ungu (Brassica oleracea L.) dalam Menurunkan Kadar Gula Darah Mencit Jantan, Skripsi, Universitas Sumatera Utara.

Widiastuti, H., 2015, Standarisasi Vitamin $\mathrm{C}$ pada Buah Bengkuang (Pachyrhizus erosus) secara Spektrofotometri UV-Vis, Jurnal Fitofarmaka Indonesia, $\mathbf{5}(1)$, 72-75. 